\title{
POPs monitoring system in Lake Baikal - impact of time or the first need?
}

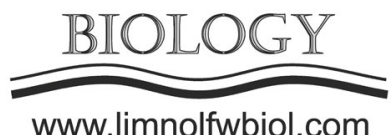

www.limnolfwbiol.com

\author{
Gorshkov A.G.*, Kustova O.V., Izosimova O.N., Babenko T.A.
}

Limnological Institute, Siberian Branch of the Russian Academy of Sciences, Ulan-Batorskaya Str., 3, Irkutsk, 664033, Russia

\begin{abstract}
Persistent organic pollutants (POPs) were first found in the fat of the Baikal seal "Phoca sibirica, Gm" in 1986. In subsequent years, studies of POPs at Baikal did not lead to the creation of a monitoring system, despite its high demand for Lake Baikal as a source of drinking water of the world value. We have proposed a solution to the scientific methodological problem of POPs control in Lake Baikal by selecting priority POPs, the optimal sampling and developing methods for determining POPs in a range of concentrations corresponding to their content in Baikal waters and meeting the requirements of serial analysis. Three classes of pollutants were selected as priority POPs, polychlorinated biphenyls (PCBs), polycyclic aromatic hydrocarbons (PAHs) and o-phthalic acid diesters (phthalates). The water-sampling scheme in the pelagic zone of the lake included five directions from the west to the east coast in three lake basins, the southern and northern extremities of the lake, the delta of the Selenga River, Maloye More strait, and Chivyrkuy and Barguzin bays. The determination of priority POPs was based on a comprehensive analysis of one sample, the volume of which did not exceed $1.0 \mathrm{~L}$, and the GC-MS/MS method in the analytic ending. Depending on the POPs concentration, the accuracy of their determination was estimated at a range of $\pm \delta$ from 10 to $35 \%$. The testing of the methodology has indicated that the POP content in the Baikal waters at the modern stage is characterized by phthalate concentrations ranging from 0.03 to $3.7 \mu \mathrm{g} / \mathrm{L}$, total PAH concentrations from 7.0 to $36 \mathrm{ng} / \mathrm{L}$, and PCB congeners from 1.4 to $7.2 \mathrm{ng} / \mathrm{L}$.
\end{abstract}

Keywords: Lake Baikal, POPs monitoring system, PCBs, PAHs, phthalates

\section{Introduction}

The first data on the presence of persistent organic pollutants (POPs) in Baikal were presented in Ts.I. Bobovnikova et al. (1986). The authors reported the discovery of polychlorinated biphenyls (PCBs) and organochlorine pesticides in the fat of the Baikal seal "Phoca sibirica, Gm". A wider range of POPs detected and investigated in Baikal was shown in a series of works carried out within the framework of the Baikal International Center for Environmental Research (Kucklik et al., 1994; 1996; Iwata et al., 1995; Nakata et al., 1995) and summarized later by M.A. Grachev (2002). At this stage researcher were mainly interested in organochlorine pollutants, since the compounds from this group are stable in environmental objects and toxic for wildlife and humans. At that time, the POP content in the lake was assessed as corresponding to the global reference level.

The monitoring studies conducted in 1992-1993 indicated that organochlorine pollutants, depending on the levels of their accumulation in the fat of the seal and in the muscles of the Baikal omul, can be represented as follows:

$\mathrm{PCB} \sim \mathrm{DDT}>$ Chlordane $>\mathrm{HCCH}>\mathrm{HCB}>>>$ PCDD, PCDF (Kucklik et al., 1994; Nakata et al., 1995), where: DDT is the sum of dichlorodiphenyltrichloroethane and its metabolites, $\mathrm{HCH}$ - hexachlorocyclohexane, HCB - hexachlorobenzene, PCDD - polychlorinated dibenzodioxins and PCDF polychlorinated dibenzofurans.

In Baikal water, the total concentrations of PCB congeners (upper water layer) were determined in the concentration range from 0.02 to $0.59 \mathrm{ng} / \mathrm{L}$ (Iwata et al., 1995) and from 0.13 to $1.9 \mathrm{ng} / \mathrm{L}$ (Kucklick et al., 1996) with the trend of their increase from the northern to the southern basin of the lake. Based on the similarity of PCB congener profiles found in the water and in the technical product "Sovol", which was produced at that time in Russia, it was concluded that PCBs enter the lake from local sources.

In subsequent years, POPs studies at Lake Baikal was focused on the catchment basin of lake, i.e. water and bottom sediments of the tributaries, soils on the coast; identification of sources; assessment of regional 
transport of POPs from the industrial zone of the Baikal region to the water area of the lake (Gorshkov and Marinaite, 2000; 2002; Marinaite and Gorshkov, 2002; Batoev et al., 2003; Tsydenova et al., 2003; 2004; Gorshkov et al., 2008; Marinaite et al., 2013; Shirapova et al., 2013a; 2013b).

\section{Results and Discussion}

In 2013-2014 within the framework of the Federal Target Program "Protection of Lake Baikal and the socio-economic development of the Baikal natural territory for 2012-2020", the specialists from the Scientific and Production Association "Taifun" and LIN SB RAS carried out monitoring of organochlorine pollutants. The study objects were the surface layer of the atmosphere, the upper water layer, bottom sediments and lake biota, and the coastal soil. According to the monitoring results, the content of PCDD and PCDF in three lake basins did not exceed $0.01 \mathrm{pg} / \mathrm{L}$; PCBs were assigned to the main organochlorine POPs in Baikal water. The monitoring also revealed the following changes in the "fate" of PCBs in Baikal over the past 20 years (Gorshkov et al., 2017a; Samsonov et al., 2017):

- the concentration of PCBs in water was 4.5 times higher relative to the maximum levels and 20 times higher relative to the minimum values recorded in 1991-1992;

- water from the middle basin of the lake differed in the minimum PCB content (Fig. 1).

The increasing concentration of PCBs in Baikal water, arose the following questions: a) an increase in the level of PCB content in Baikal waters is the result of their slow accumulation over the entire period or a salvo injection during a short period of time, b) the current level of PCB content in Lake Baikal will continue in the future because of the sustainability of pollutants of this class in aquatic ecosystems, or its gradual decrease is possible. Due to the lack of a monitoring system for POPs in the lake waters and systematic monitoring data, there are no answers to these questions (Fig. 2).

Identification of PCB sources, which determined the growth of PCB content in the lake waters, has not been completed as well. According to (Samsonov et al., 2017), the global atmospheric transport is the dominant channel for the entry of PCBs into Baikal waters, since "there are no significant variations in the qualitative composition of congeners identified in the composition of water samples" collected in the pelagic zone of the lake. At the same time, an increased content of congeners with a high degree of chlorination $(11-19 \%$ of the total amount of PCB) in water samples from Southern Baikal indicating the persistence of local PCB sources was observed in (Gorshkov et al., 2017a).

The group headed by E.N. Tarasova contributed significantly to the study of superecotoxicants - PCDD and PCDF, in the Baikal ecosystem (Mamontova et al., 1997; 2001; 2013; Tarasova et al., 1997; Mamontov et al., 2000; 2013; Kuzmin, 2005). In particular, should note an estimate of the proportion of coplanar PCBs in

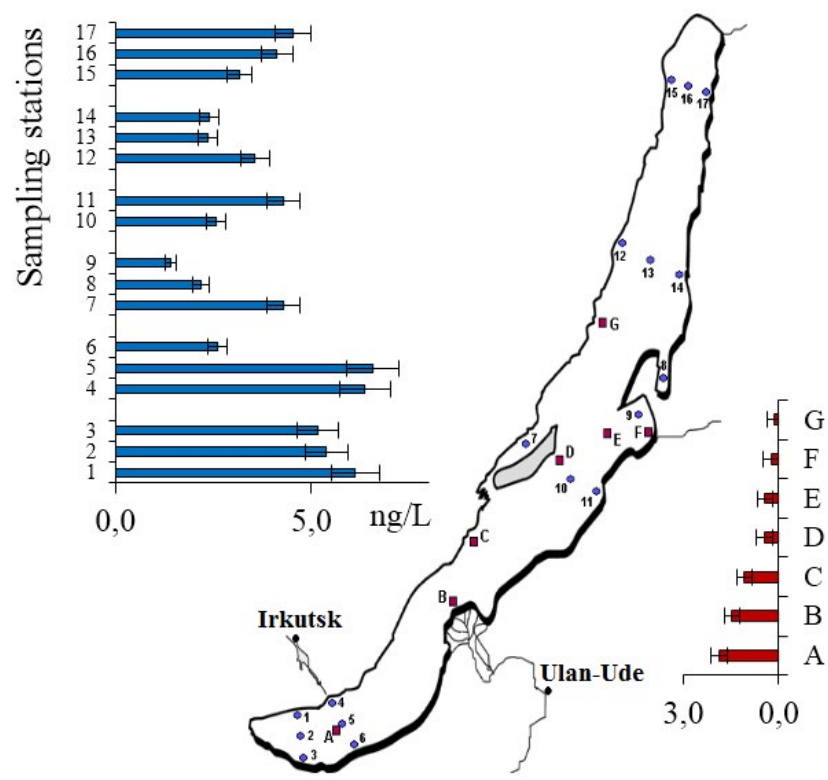

Fig. 1. Map of water sampling and total concentrations of PCB congeners (ng/L) detected duringthe expeditions conducted in 1993 - (Kucklick et al, 1996) and 2015 - . (Gorshkov et al., 2017a).

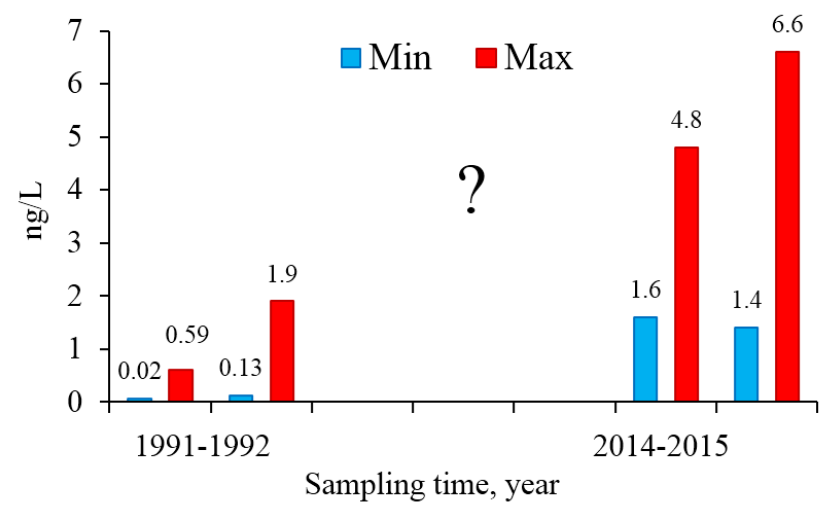

Fig. 2. Levels of total PCB concentrations (ng/L) detected during independent expeditions in 1992-1993 (Iwata et al., 1995; Kucklick et al, 1996) and 2014-2015 (Gorshkov et al., 2017a; Samsonov et al., 2017).

the total equivalent toxicity of PCDD, PCDF and PCB (TEQ1998), which exceeds $70 \%$ in commercial fish (Mamontov et al., 2000) and 50\% among the people examined in the Baikal region (Shelepchikov et al., 2012).

According to a study conducted by LIN SB RAS, polycyclic aromatic hydrocarbons (PAHs) can be also included in the Baikal waters purity control system. The presence of PAHs in the lake waters is associated with both anthropogenic sources: organized emissions of boiler houses burning coal in cities and settlements on the coast; emissions from the Baikal fleet, as well as from natural sources. The latter include forest fires at the Baikal natural territory and natural oil shows.

In the upper water layer of the pelagic zone of the lake, PAHs showed rather narrow range of total concentrations, from 7.0 to $36 \mathrm{ng} / \mathrm{L}$ (results of $\mathrm{PAH}$ monitoring in the waters of Baikal in the spring of 2015 and 2016). The composition of PAHs was dominated by naphthalenes; their total quantity reached $15 \mathrm{ng} / \mathrm{L}$. In the fraction of detected PAHs, this value was 50- 
70\%. During the monitoring of Baikal waters in 2016 (autumn), the samples from the upper water layer of the southern and middle basins were characterized by a high content and extreme quantity of PAHs in individual samples, exceeding the average level for lake waters, by 5-15 times (Fig. 3). The composition of PAHs in these water samples also differed essentially: phenanthrene, pyrene, fluoranthene dominated in the PAHs fraction (up to $90 \%$ of the detected $\Sigma \mathrm{PAHs}$ ). Considering that during the water sampling the Siberian taiga was burning on the coast of the lake, and pyrene and fluoranthene are indicators of wood burning products, an increase in the PAH content in the upper water layer may be a result of their entry from the atmosphere polluted by forest smoke.

During 2006-2016, from 10 to 32 cases of fires occurred annually; the forest area covered by fires estimated from 116 to 11,000 hectares per 1 million hectares of territory. For the period from 2014 to 2016, the total area of forest fires covered 26,720 hectares of territory representing $80 \%$ of the total area of all fires for the past 10 years (State Report, 2017). In the absence of a system of continuous control, it is difficult to assess the contribution of PAHs in Baikal waters from forest fires, considering the spatial and temporal variability of this natural source.

Another natural source of PAHs in the Baikal ecosystem is natural oil seepages characterized by oil entering the lake water in a volume of 2 to 4 tons/ year (Khlystov et al., 2007; Kontorovich et al., 2007). In Central Baikal (Cape Gorevoy Utes), the pollution of surface water with oil hydrocarbons was recorded for an area of no more than $1 \mathrm{~km}^{2}$. The study of this Baikal phenomenon (Gorshkov et al., 2010) indicated that oil is fractionated at the bottom-water interface, and the segregation of heavy oil fractions takes place forming asphalt towers. A high-molecular PAHs, including such maximally toxic ones as benzo[a]pyrene, and dibenzo[a, h]anthracene, are accumulated in the asphalt towers, thus preserving the water purity of Lake Baikal. A light fraction of oil enriched with $n$-alkanes migrates to the water column and to the water surface

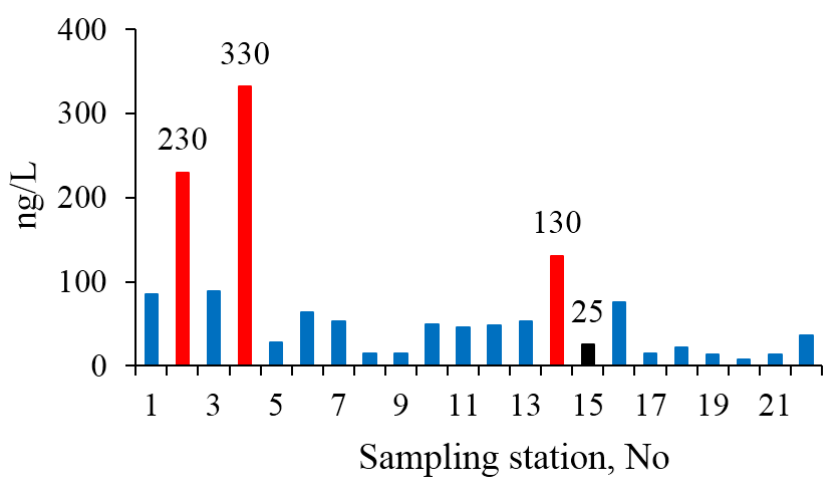

Fig. 3. Total PAH concentrations (ng/L) in the upper water layer of the Baikal pelagic zone $(5 \mathrm{~m})$. Water sampling in 2016 (September-October). - samples with an extreme content of PAHs; - PAHs content in the upper water layer $(5 \mathrm{~m})$ in the natural oil seepages of Central Baikal (Cape Gorevoy Utes). of the lake, where $n$-alkanes are readily biodegraded by the Baikal microbial community (Pavlova et al., 2012). Data on laboratory experiments showed PAHs accumulation by phytoplankton from the light oil fraction (Shishlyannikov et al., 2017). Obviously, these processes limit of the area of pollution of Baikal waters with petroleum hydrocarbons, the purity of water, the composition and quantity of PAHs outside the boundaries of oil seepages.

The study of the diesters of $o$-phthalic acid (phthalates) in the aquatic ecosystem of Lake Baikal allowed their including in the POPs control system as priority ones. Phthalates are the most important products of the chemical industry. The volume of their production in the world reaches 5-6 million tons per year, up to $80 \%$ of synthesized phthalates are used as plasticizers for plastics. Plasticizers do not form chemical bonds with the polymer and are capable of passing into the environment through free migration during the operation and recycling of polymer products. Moreover, the entry of phthalates into water bodies is possible not only from anthropogenic sources, but also as a result of the activity of bacteria and algae in aquatic ecosystems (Chen et al., 2004; Namikoshi et al., 2006). The first monitoring data of phthalates in Baikal showed a high heterogeneity of their distribution in the three depressions of the lake, sharp seasonal variability of concentration levels, which suggested various sources of this group of pollutants, anthropogenic and biogenic (Fig. 4) (Gorshkov et al., 2017b).

Notably, the POPs studies at Lake Baikal conducted since their discovery in the lake ecosystem but have not ended with the creation of a monitoring system, despite its high demand for Lake Baikal as a source of world-class drinking water containing up to 23,000 $\mathrm{km}^{3}$ of water or $\sim 20 \%$ of surface fresh water of the world. A number of organizational issues in this direction were resolved by Irkutsk Hydrometeorology and Environmental Monitoring Department, but the scientific methodological problem of POPs control at Lake Baikal remained, which consists of the following:

- certified methods, state and international standards do not meet the requirements of POPs monitoring in Baikal water, since the lower limits of detectable concentrations of pollutants in these regulatory documents are higher than their content in samples of Baikal water (RD 52.44.590, 2016; GOST R 54503-2011; ISO 28540:2011; MP UVK 1.89-2014);

- an increase in the volume of samples taken to determine POPs at the trace and ultra-trace concentrations is practically unrealizable within the framework of monitoring considering the volume of the water body of Baikal and the required number of samples taken to obtain reliable information about the level of the lake water pollution.

The stated problem of POPs monitoring can be eliminated by solving the following tasks: a) selecting priority POPs for monitoring in Baikal waters; b) search for the optimal sampling option; c) development 

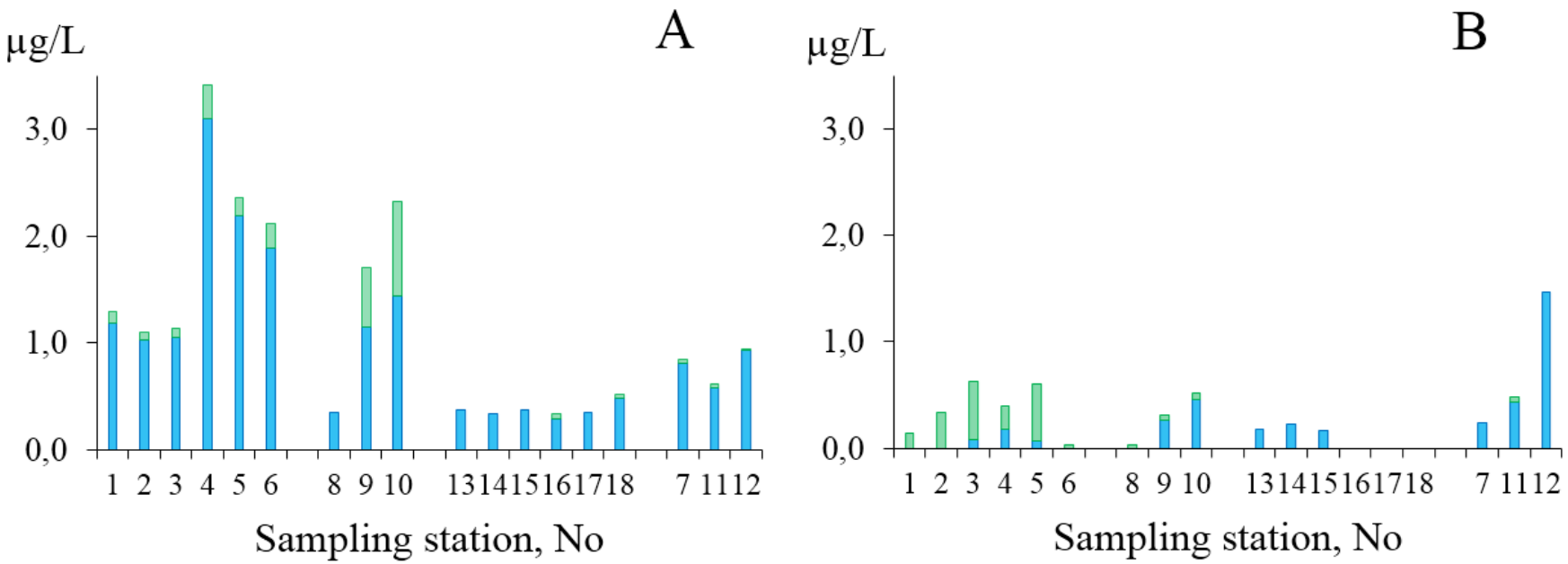

Fig. 4. The total concentration of phthalates ( $\mu \mathrm{g} / \mathrm{L})$ in the Baikal pelagic zone, horizon 5 m. Monitoring: 2016, spring (A) and autumn (B). Phthalates: DBP - and DEHP -

of methods for the determination of POPs in a range of concentrations corresponding to the content of POPs in the waters of Baikal and meeting the requirements of serial analysis.

The priority pollutants in the POPs monitoring system in Baikal waters should include three classes of compounds, PCBs, PAHs and phthalates, classified by the Stockholm Convention as POPs. PCBs were distinguished as the dominant organochlorine pollutants, and PAHs by the presence of natural sources. Phthalates in the water of Baikal were characterized by a level of two to three orders of magnitude higher than the concentrations of PAH and PCB, as well as sharp seasonal and spatial variability. Under these conditions, the determination of trends and dependences of the presence of POPs in the lake ecosystem is possible during their systematic monitoring.

We proposed the water sampling (Fig. 1) according to a scheme that includes 5 sections in three basins of the lake, three station at each section, $3 \mathrm{~km}$ from the western shore, $3 \mathrm{~km}$ from the eastern shore and 1 point in the center of the section, as well as sampling station in northern and southern extremity of the lake, in the area of the Selenga delta, Maloye More strait and in Chivyrkuy and Barguzin bays. In the three basins of the lake, we selected station for sampling from deep horizons (central points of the sections) from 4 to 6 samples depending on the depth of the lake at the sampling site.

To determine the priority POPs in Baikal waters, we have developed methods based on the extraction of pollutants in hexane and analysis of extracts using the GC-MS/MS method in the analytical ending. We suggest the determination of PCB, PAH and phthalates as part of a comprehensive analysis of a single sample, the volume of which does not exceed $1.0 \mathrm{~L}$. The accuracy of measurements was estimated by the range of $\pm \delta$ from 10 to $35 \%$ depending on the analytes concentration (Gorshkov et al., 2017a; Izosimova, 2018; Kustova and Gorshkov, 2018). The GC-MS/MS method is highly sensitive and reliable for dtermination POPs, as well as included in the number of arbitration methods selected for the analysis of environmental objects.
This methodological approach was tested during the 2015-2016 expeditions around Baikal. The results indicate a modern level of priority POPs content in Baikal waters:

- two phthalates were found in the water of Baikal, di-n-butyl phthalate and di-(2-ethylhexyl)phthalate, the content of which corresponds to the concentration range from 0.03 to $3.7 \mu \mathrm{g} / \mathrm{L}$;

- the content of $\Sigma$ PAHs in the upper water layer of the Baikal pelagic zone ranged from 7.0 to 36 $\mathrm{ng} / \mathrm{L}$. The composition of PAHs was characterized by the dominance of naphthalenes, and their number reached $50-70 \%$ in the fraction of PAHs. There was no benzo[a]pyrene at the level of $0.1 \mathrm{ng} / \mathrm{L}$, which was 50 times lower than maximum permissible concentration determined for this carcinogen in drinking water;

- in the waters of the lake, from 24 to 34 PCB congeners were identified ( $\Sigma$ PCB 1.4-7.2 ng/L). For continuous monitoring, 7 indicator congeners were introduced into practice.

\section{Conclusion}

It should be stated that the POPs monitoring system for the waters of Lake Baikal is not impact of time, but a first need. Choosing PCBs, PAHs and phthalates as priority pollutants, optimal scheme for water sampling, and new analytical solutions developed for determining POPs in the lake water can serve as a scientific basis for the POPs monitoring system in Lake Baikal. The data on the POPs content in Baikal at the present stage obtained from testing the proposed control system can be used as a starting point when considering trends in the "fate" of POPs in the future.

\section{Acknowledgments}

The work was carried out within the framework of basic budget funding (project: 0345-2016-0008 (AAAA-A16-116122110065-4)) and financial support 
from the Russian Fund for Basic Research and the Government of the Irkutsk Region (project No. 17-45388077). Chromato-mass-spectrometric analysis was carried out in Collective Instrumental Center «Ultramicroanalysis».

The authors are sincerely grateful to the staff of the LIN SB RAS: Yu. R. Zakharova, I.S. Mikhailov and O.N. Pavlova for their help in sampling water in the pelagic zone of Lake Baikal; S.M. Shishlyanikov for the participating in the discussion of the results.

\section{References}

Batoev V.B., Weissflog L., Wenzel K.-D. et al. 2003. Pollution of the Basin of the Lake Baikal: polyaromatic hydrocarbons. Chemistry for Sustainable Development 11: 837-842.

Bobovnikova Ts.I., Virchenko E.P., Dibtseva A.V. et al. 1986. Water mammals are indicators of the presence of organochlorine pesticides and polychlorinated biphenyls in the aquatic environment. Hydrobiological Journal 22: 63-68.

Chen C.Y. 2004. Biosynthesis of di-(2-ethylhexyl) phthalate (DEHP) and di-n-butyl phthalate (DBP) from red alga Bangia atropurpurea. Water Research 38: 1014-1018. DOI: 10.1016/j.watres.2003.11.029

Gorshkov A.G., Marinayte I.I. 2000. Monitoring of the ecological toxicants in the environmental objects of Baikal region. Part 1. Determination of polycyclic aromatic hydrocarbons in the aerosol of industrial centers (on the example of the Irkutsk city). Atmospheric Oceanic Optics 13: 889-902.

Gorshkov A.G., Marinaite I.I. 2002. Investigation of PAH in atmospheric aerosols and precipitation's of East Siberia. In: Barnes I. (Ed.), Global atmospheric change and its impact on regional air quality. Netherlands, pp. 203-208.

Gorshkov A.G., Mikhailova T.A., Berezhnaya N.S. et al. 2008. Needle of Scotch pine (Pinus sylvestris L.) as a bioindicator for atmospheric pollution with polycyclic aromatic hydrocarbons. Chemistry for Sustainable Development 16: 155-162.

Gorshkov A.G., Khlystov O.M., Zemskaya T.I. et al. 2010. Oil fractionation in deep-water areas of oil shows of Lake Baikal. In: Proceedings of the Conference the Successes of Organic Geochemistry, pp. 116.

Gorshkov A.G., Kustova O.V., Dzyuba E.V. et al. 2017a. Polychlorinated biphenyls in Lake Baikal ecosystem. Chemistry for Sustainable Development 25: 269-278. DOI: 10.15372/ KhUR20170305

Gorshkov A.G. Babenko T.A., Izosimova O.N. et al. 2017b. Priority phthalates in the Lake Baikal pelagic zone and coastal area. Chemistry for Sustainable Development 25: 375-383. DOI: 10.15372/KhUR20170403

GOST R 54503-2011. 2013. Water. Methods for determining the content of polychlorinated biphenyls. ISO 6468:1996 (NEQ). Moscow: Standartinform. (in Russian)

Grachev M.A. 2002. On the current state of the ecological system of Lake Baikal. Novosibirsk: Publishing house SB RAS. (in Russian)

ISO 28540:2011. International standard. Water quality. Determination of 16 polycyclic aromatic hydrocarbons (PAH) in water. Method using gas chromatograph with mass spectrometric detection.

Iwata H., Tanabe S., Ueda K. et al. 1995. Persistent organochlorines residues in air, water, sediments, and soils from the Lake Baikal Region, Russia. Environmental Science Technology 29: 792-801. DOI: 10.1021/es00003a030

Izosimova O.N. 2018. A methods for control of polycyclica hydrocarbons in the Lake Baikal water. In: International Conference Freshwater Ecosystems - Key Problems, pp. 174-175.
Khlystov O.M., Gorshkov A.G., Egorov A.V. et al. 2007. Oil in the Lake of World Heritage. Doklady Earth Sciences 415: 682-685. DOI: 10.1134/S1028334X07050042

Kucklik J.R., Bidleman T.F., McConnell L.L. et al. 1994. Organochlorines in the water and biota of Lake Baikal, Siberia. Environmental Science Technology 28: 31-37. DOI: 10.1021/es00050a006

Kucklick J.R., Harvey H.R., Ostrom P.H. et al. 1996. Organochlorine dynamics in the pelagic food web of Lake Baikal. Environmental Toxicology and Chemistry 15: 13881400. DOI: $10.1002 /$ etc.5620150819

Kustova O.V., Gorshkov A.G. 2018. Methods of organochlorine pollutants monitoring in water of Lake Baikal. In: International Conference Freshwater Ecosystems - Key Problems, pp. 213.

Kuzmin M.I. 2005. Polychlorinated biphenyls (PCBs) in the Baikal region: sources, long-range transport and risk assessment (results of grant INTAS 2000-00140). Irkutsk: Publishing house of the Institute of Geography of the SB RAS. (in Russian)

Mamontov A.A., Mamontova E.A., Tarasova E.N. et al. 2000. Tracing the Sources of PCDD/Fs and PCBs to Lake Baikal. Environmental Science Technology 34: 741-747. DOI: 10.1021/es991047r

Mamontov A.A., Mamontova E.A., Tarasova E.N. et al. 2015. The change of polychlorinated biphenyls content in soil of coastal zone of Lake Baikal in 1997-2012. Russian Journal of General Chemistry 85: 2945-2951. DOI: 10.1134/ S1070363215130125

Mamontova E.A., Mamontov A.A., Matorova N.I. et al. 1997. PCB in snow of the Baikal region. Organohalogen compounds 32: 72-75.

Mamontova E.A., Mamontov A.A., Matorova N.I. et al. 2001. Pollution of PCBs of snow cover in Irkutsk region. Geography and Natural Resources 4: 133-136. (in Russian)

Mamontova E.A., Mamontov A.A., Tarasova E.N. et al. 2013. Polychlorinated biphenyls in surface soil in urban and background areas of Mongolia. Environmental Pollution 182: 424-429. DOI: 10.1016/j.envpol.2013.08.001

Marinayte I.I., Gorshkov A.G. 2002. Monitoring of the ecological toxicants in the environmental objects of Baikal region. Part 2. Polycyclic aromatic hydrocarbons in snow cover of industrial center. Atmospheric Oceanic Optics 15: 405-410.

Marinayte I.I., Gorshkov A.G., Taranenko E.N. et al. 2013. Distribution of Polycyclic Aromatic Hydrocarbons in Natural Objects over the Territory of Scattering the Emissions from the Irkutsk Aluminum Plant (Shelekhov City, the Irkutsk Region). Chemistry for Sustainable Development 20: 135-146.

MP UVK 1.89-2014. Metodika izmereniy massovoy kontsentratsii efirov ftalevoy kisloty v pit'yevykh i prirodnykh vodakh metodom khromato-mass-spektrometrii [Measurement procedure of mass concentration of phthalic acid esters in drinking and natural waters by chromatography-mass spectrometry]. FR.1.31.2015.20196. Ufa: Ufavodocanal. (in Russian)

Nakata H., Tanabe S., Tatsukawa R. et al. 1995. Persistent organochlorine residues and their accumulation kinetics in Baikal seal (Phoca sibirica) from Lake Baikal, Russia. Environmental Science Technology 29: 2877-2885. DOI: 10.1021/ es00011a026

Namikoshi M., Fujiwara T., Nishikawa T. et al. 2006. Natural abundance $14 \mathrm{C}$ content of dibutyl phthalate (DBP) from three marine algae. Marine Drugs 4: 290-297.

Pavlova O.N., Lomakina A.V., Gorshkov A.G. et al. 2012. Microbial communities and their ability to oxidize $n$-alkanes in the area of release of gas and oil containing fluids in Mid-Baikal (Cape Gorevoi Utes). Biology Bulletin 39: 458463. DOI: $10.1134 /$ S1062359012050123 
$\mathrm{RD}$ 52.44.590. 2016. Massovaya kontsentratsiya prioritetnykh komponentov politsiklicheskikh aromaticheskikh uglevodorodov $\mathrm{v}$ probakh atmosfernykh osadkov i poverkhnostnykh vod. Metodika izmereniy metodom vysokoeffektivnoy zhidkostnoy khromatografii Rosgidromet [Mass concentration of priority components of polycyclic aromatic hydrocarbons in samples of atmospheric precipitation and surface waters. Measurement procedure by High Performance Liquid Chromatography]. Moscow: Rosgidromet. (in Russian)

Samsonov D.P., Kochetkov A.I., Pasynkova E.M. et al. 2017. Levels of Persistent Organic Pollutants in the Components of the Lake Baikal Unique Ecosystem. Russian Meteorology and Hydrology 42: 345-352. DOI: 10.3103/ S1068373917050119

Shelepchikov A.A., Chernyak Yu.I., Brodsky E.S. et al. 2012. Polychlorinated dibenzo-p-dioxins, dibenzofurans and biphenyls in blood serum of firefighters of Irkutsk oblast. Sibirskiy meditsinskiy zhurnal (Irkutsk) [Siberian Medical Journal] 3: 53-59. (in Russian)

Shirapova G.S., Utyuzhnikova N.S., Rabina O.A. et al. 2013a. Contamination of the Lake Baikal Basin with polyaromatic hydrocarbons: the Gusinoye Lake. Chemistry for Sustainable Development 20: 189-195.
Shirapova G.S., Utyuzhnikova N.S., Rabina O.A. et al. 2013b. Contamination of the Lake Baikal Basin by organochlorine pesticides and polychlorinated biphenyls: the Gusinoye Lake. Chemistry for Sustainable Development 20: 197205.

Shishlyannikov S.M., Nikonova A.A., Klimenkov I.V. et al. 2017. Accumulation of petroleum hydrocarbons in intracellular lipid bodies of the freshwater diatom Synedra acus subsp. radians. Environmental Science and Pollution Research 24: 275-283. DOI 10.1007/s11356-016-7782-y

State Report. 2017. On the status and protection of the environment of the Irkutsk region in 2016. Irkutsk: Megaprint LLC.

Tarasova E.N., Mamontov A.A., Mamontova E.A. et al. 1997. Polychlorinated dibenzo-p-dioxins (PCDDs) and dibenzofurans (PCDFs) in Baikal seal. Chemosphere 34: 2419-2427.

Tsydenova O.V., Batoev V.B., Weissflog L. et al. 2003. Pollution of the Lake Baikal Basin: Organochlorine Pesticides. Chemistry for Sustainable Development 11: 349-352.

Tsydenova O.V., Minh T.V., Kajiwara N. et al. 2004. Recent contamination by persistent organochlorines in Lake Seal (Phoca Sibirica) from Lake Baikal, Russia. Marine Pollution Bulleten 48: 749-758. DOI: 10.1016/j.marpolbul.2003.10.027 